a caricature of natural selection. $\mathrm{He}$ appealed for the study of individual life forms.

Prof. A. C. Seward considered that the great uniformity of the curves presented by Dr. Willis and Mr. Udny Yule was suspicious, for Nature had not been uniform. He pointed out that, as regards conifers and ferns, study showed that the forms existing now in restricted areas were the oldest and not the youngest.

Mr. Julian Huxley contended that many factors played a part in evolution. Species characters should be analysed by the methods of genetics and physiology before it could be said which were useless. Apparently useless characters in the Gipsy moth were correlated with physiological differences, such as rate of growth, which harmonised with the environment.

Prof. R. Ruggles Gates considered that Dr. Willis's view was a corollary of the mutation hypothesis, and emphasised the importance of the extinction of forms as a factor in evolution.

Prof. W. J. Dakin suggested that biologists were on the threshold of a new line of study of evolution from the physico-chemical side. He believed that the faculty of evolution was as much a character of the organism as irritability or reproduction, and pointed out that natural selection was really natural elimination, the production of characters being inherent properties.

Dr. A. B. Rendle said it was almost impossible to say what characters were useful or not, and, in view of the limited space available, considered that the multiplication of genera and species in geometrical progression was unlikely.

Prof. J. Stanley Gardiner agreed that evolution was an inherent property of protoplasm, and raised the question as to why forms of life died out. He expressed approval of the main thesis of "Age and Area."

In reply, Dr. J. C. Willis pointed out that there must be some reason for the uniformity of expression as given in his statistical work. He accepted the phrase "Natural Elimination" instead of "Natural Selection."

In concluding the discussion, Prof. H. H. Dixon pointed out that both "Natural Selection" and "Age and Area" were essentially truisms, but none the less required explicit statement and demonstration.

\title{
Effects of Local Conditions on Radio Direction-finding.
}

THE methods used for finding the direction in which Hertzian waves are incident at a radio station have now attained a high accuracy, the maximum error being well under one degree. It does not follow, however, that the methods give the direction of the sending station to the same accuracy. The waves sent out may have suffered reflections from all kinds of conductors before they reach the receiving station. Hence, especially at night-time, the apparent direction generally differs very appreciably from the true direction. A preliminary report on this subject, communicated by the Radio Research Board, was read on November 8 to the Radio section of the Institution of Electrical Engineers by Messrs. Smith-Rose and Barfield. They classify the causes of distortion under two heads: First, those which are vaguely classed as night-effects and occur between sunset and sunrise. They are sometimes as large as $20^{\circ}$, and little is known as to their cause. Hence in practice radio-direction finding is restricted to day-time. The second causes of error are those due to conducting substances in the immediate neighbourhood of the search coil. In one experiment a metal tube $50 \mathrm{ft}$. long, semicircular in cross-section, and of radius $3 \mathrm{ft}$. 6 in. was used. When the coil was at a distance of $I_{5} \mathrm{ft}$. from either end errors became appreciable, and when placed ${ }_{5} \mathrm{ft}$. inside the tube the error was as great as $29^{\circ}$.

Experiments were also made on board ship, as radio-direction finding is of great value in navigation.
It was found that when the waves came fore-and-aft or athwart the ship there was no error, but that in intermediate positions the errors were sometimes as great as $22^{\circ}$. As these errors are approximately constant, corrections can be applied as in the case of the magnetic compass. Curiously enough it was found that underground metal work in the neighbourhood had a very appreciable effect on the apparent direction of the incoming waves. The Aberdeen University direction-finding station, for example, was erected on what was thought to be a favourable site. The errors found, however, indicated the existence of a long strip of metal in the neighbourhood in a definite direction. The authors investigated the cause and found that a sewer in the neighbourhood, which was in the given direction, was supported by a strip of steel $6 \mathrm{ft}$. wide, $300 \mathrm{ft}$. long, and $8 \mathrm{ft}$. below the surface.

Overhead wires also caused appreciable but variable errors, which the authors traced to variations of the telegraph and telephone circuits when in use. They investigated the errors produced by tuned aerials and trees. Trees when damp have small resistance, and so the oscillations set up in them affect the direction of the waves. A row of damp trees forms a very good conducting screen. It was noticed that the waves showed a tendency to move round large conductors. Owing to variable meteorological conditions a very large number of experiments had to be made before definite results were obtained. The authors are continuing theri investigations.

\section{New X-ray Department at Manchester.}

SIR HUMPHRY ROLLESTON, president of the Royal College of Physicians and of the Röntgen Society, opened on November I 8 the new X-ray department of the Manchester Royal Infirmary, which is probably the most completely equipped department of its kind in this country. This has been made possible by two separate gifts of $5000 l$. one by Mr. Robert McDougall and the other by an anonymous benefactor.

The occasion coincided with a joint provincial meeting at Manchester of the Röntgen Society and the Electrotherapeutics Section of the Royal Society of Medicine; and a considerable number of members took the opportunity of inspecting the new equipment, which has been installed by Messrs. Watson and Sons under the direction of Dr. A. E. Barclay, senior radiologist to the Infirmary

The new department is on the ground-floor, is well lighted and ventilated, possesses generous head room, and is cheerfully decorated, all features which are

$$
\text { NO. } 2770 \text {, VOL. I IO] }
$$


stressed in the recommendations of the X-ray and Radium Protection Committee. Indirect lighting is employed, the ceilings being painted with white enamel.

Throughout the building high-tension wires are abolished. They are replaced by stout aluminium tubing, which eliminates brush discharges and prevents the formation of ozone, now known to be prejudicial to the health of the operators.

Most of the X-ray bulbs are contained in boxes which are covered with an adequate thickness of sheet lead. In addition, the walls are coated with a plaster containing a large admixture of barium sulphate, the result being a wall giving protection equivalent to that of about $8 \mathrm{~mm}$. of lead.

Coolidge tubes and closed-core high-tension transformers are the order of the day, except in the treatment department, where the existing induction coils have been brought up-to-date.

In the screening-room a Sunic ro K.V.A. oilimmersed transformer is installed. The new intensive deep therapy treatment of cancer is catered for by two separate 200,000 -volt outfits, each of the twin-coil type--one a German set with dry insulation by Maison Schaerer, the other of the oil-immersed type by Newton and Wright.

There are a number of unusually elaborate screening-stands and couches, a novel development being the Potter Bucky couch, in which a lead grid is inserted between the patient and the photographic plate. The grid, while allowing direct $\mathrm{X}$-rays from the bulb to pass, prevents the majority of the scattered radiation from reaching the plate, to the marked benefit of definition. A special portable $\mathrm{X}$-ray equipment is provided for use in the wards of the hospital in cases where it is inadvisable to move the patient.

The lay-out of the department is well-nigh a model of its kind, being arranged so that the work progresses automatically to its finality. The day of black-painted walls for dark rooms is over; instead, we find a cheery lofty room which can readily be flooded with daylight when the room is not in use. Thermostatic control of the developing and fixing solutions, etc., is provided. There is also a fullyequipped demonstration room, so that doctors and students can watch the examination of cases without hampering the work. This demonstration room is also provided with a stereo-motorgraph, an ingenious instrument which automatically changes lantern slides by a press-button, so that the lecturer is independent of a lantern operator. The proportion of infirmary patients requiring $\mathrm{X}$-ray examination is one in five, so that business-like and orderly arrangements are very essential.

At the joint meeting Prof. Jacobaeus of Stockholm, Prof. W. L. Bragg and Prof. A. V. Hill, among others, contributed papers; and the enterprise of the two societies in departing from precedent by holding a meeting in the provinces met with great local appreciation and support.

\section{University and Educational Intelligence.}

Aberdeen.-Dr. A. W. Gibb has been appointed to the newly founded Kilgour chair of geology. This foundation is derived from a bequest under the will of the late Dr. Alexander Kilgour of South Loirston, supplemented in the will of his son, through whose death it has now become available. In accordance with the terms of the trust deed, junior and senior scholarships in natural science have also been instituted. Prof. Gibb, who has an intimate knowledge of the geology of the north of Scotland, has been in charge of the teaching of the subject since I899, first as a member of the staff of the natural history department, and since 1908 as head of an independent department of geology. The teaching of the subject in Aberdeen is associated with the names of James Nicol and Alleyne Nicholson.

Prof. E. W. Hobson has completed, during the present month, his second series of Gifford lectures on "The Domain of Natural Science." In this series, which concludes the course, he has reviewed the whole field of natural science, and has dealt with its relation to general thought and to theism. The lectures will appear in book form.

Lrverpool.-We understand that Prof. F. Carey is to retire at the end of the present session. Prof. Carey is head of the department of pure mathematics at the University, and was one of the original professors on the first staff of the University College.

THE Strasbourg correspondent of the Times states that the diploma of doctor honoris causa of the University of Strasbourg has been conferred upon Sir James Frazer, author of "The Golden Bough."

According to the Paris correspondent of the Times, the degree of doctor honoris causa of the University of Paris has been conferred on the following: Prof. Bordet, professor of bacteriology in the University of Brussels ; Prof. M. Lugeon, professor of geology in the University of Lausanne; and Prof. A. Michelson, professor of physics in the University of Chicago.

By the will of Sir William Stevenson Meyer, High Commissioner for India and formerly Chief Secretary to the Government of Madras, who died on October Io last, sums of $3000 l$. each are bequeathed to University College, London, "for the encouragement of proficiency in European history and in the history and geography of India," and to the University of Madras "for promoting the study of history and economics."

A CONFERENCE on the teaching of science in schools and colleges, which owed its initiation to Miss Winifred Smith, president of the Association of University Women Teachers, and its organisation to the joint efforts of the Association of Science Teachers and the A.U.W.T., was held on Saturday, November 25 , at University College. During the morning session, with Miss Smith in the chair, the more general aspects of science teaching and the relationship between the work in the school and in the university were discussed. In the opening paper Sir William Tilden dealt with science in the school and raised a plea for work of wider and less specialised type, with a place for the history of the growth of knowledge. His personal reminiscences added much to the interest of the paper. Sir William Bayliss and Prof. J. R. Partington both expressed themselves in hearty support of wider rango in the science work. The last speaker, from the point of view of university work, considered that the more specialisation was pushed in the school, the worse the result later. The condemnation of specialisation was continued in the papers of both Miss Thomas and of Miss Drummond. The first speaker dealt with the preparation of the student for the work of teaching science and deplored the tendency to specialise too early at the university; she considered the conditions of the Burnham scales enhanced this. The afternoon session included a paper upon the teaching of biology by Mr. A. G. Tansley, and papers upon 